\title{
O Condomínio Cidade Madura: um estudo de caso de uma nova maneira de morar da pessoa idosa brasileira
}

The City Mature Condominium: a case study of a new way of dying of the old brazilian person

El Condominio Cidade Madura: un estudio de caso de una nueva forma de vida para los ancianos brasileños

Eleusy Natália Miguel

Simone Caldas Tavares Mafra

\begin{abstract}
RESUMO: O envelhecimento populacional é um fenômeno vivenciado em todo o mundo. No Brasil, esse processo é relativamente recente, embora esteja ocorrendo de maneira acelerada. Em relação aos fatores determinantes do envelhecimento, destacamse os tipos de moradia, que podem influenciar diretamente na longevidade de um indivíduo. Diante do breve exposto, objetiva-se evidenciar as condições de habitação como fator influente na vida dos idosos residentes no Condomínio Cidade Madura, implantado em João Pessoa, capital do estado da Paraíba. Para tanto, empregam-se, como metodologia, a observação direta, o estudo de caso e o registro fotográfico. Nota-se que a iniciativa é um avanço na área de habitação para a pessoa idosa, especialmente para os de baixa renda. Conclui-se, portanto, que o condomínio atende razoavelmente às questões físicas da moradia.
\end{abstract}

Palavras-chave: Pessoa Idosa; Habitação da Pessoa Idosa; Envelhecimento no Brasil. 
ABSTRACT: Population aging is a phenomenon experienced worldwide. In Brazil, this process is relatively recent, although it is happening at an accelerated rate. Regarding the determinants of aging, the types of housing stand out, which can directly influence the individual's longevity. Given the brief exposed, the objective is to highlight housing conditions as an influential factor in the lives of the elderly living in Condomínio Cidade Madura, located in João Pessoa, capital of the state of Paraíba. For that, direct observation, case study and photographic record are used as methodology. It is noted that the initiative is an advance in the housing area for the elderly, especially for the lowincome. It is concluded, therefore, that the condominium meets reasonably the physical issues of housing.

Keywords: Elderly Person; Housing of the Senior Citizens; Aging in Brazil.

RESUMEN: El envejecimiento de la población es un fenómeno experimentado en todo el mundo. En Brasil, este proceso es relativamente reciente, aunque está ocurriendo a un ritmo acelerado. En cuanto a los determinantes del envejecimiento, se destacan los tipos de vivienda, que pueden influir directamente en la longevidad del individuo. Dado el informe expuesto, el objetivo es destacar las condiciones de vivienda como un factor influyente en la vida de los ancianos que viven en Condomínio Cidade Madura, ubicado en João Pessoa, capital del estado de Paraíba. Para eso, la observación directa, el estudio de caso y el registro fotográfico se utilizan como metodología. Cabe señalar que la iniciativa es un avance en el área de vivienda para personas mayores, especialmente para los de bajos ingresos. Se concluye, por lo tanto, que el condominio cumple razonablemente los problemas físicos de la vivienda.

Palabras clave: Persona de edad avanzada; Vivienda para ancianos; Envejecimiento en Brasil.

\section{O envelhecimento e a Habitação}

O envelhecimento populacional é um fenômeno evidenciado em todo o mundo. No Brasil, esse processo tem se estabelecido de maneira acelerada e plural, em razão das especificidades de um país com dimensão continental, como é o território brasileiro. 
Essa mudança demográfica, em que se nota um aumento significativo na população idosa em comparação à infantil, decorre, principalmente, da diminuição das taxas de mortalidade associada à queda de fecundidade, além da evolução da medicina, tanto no âmbito preventivo quanto no curativo. Trata-se de um fenômeno conhecido como "transição demográfica" (Camarano, Kanso, \& Mello, 2004; Miguel, Mafra, \& Fontes, 2016).

A modificação populacional confere ao país urgência no atendimento à pessoa idosa, o que acarreta profundas mudanças em termos de demandas por saúde, habitação, educação, previdência, cultura, lazer, entre outras. Estes são requisitos fundamentais para o favorecimento de um envelhecimento ativo e saudável (Fonseca, 2016).

A partir de tal perspectiva, a habitação possui papel relevante ao oferecer proteção física ao indivíduo. Perracini (2006) explica que a moradia propicia o desenvolvimento de um vínculo com o seu morador, e essa relação afetiva pode ser positiva ou negativa, em razão das características dessa moradia. $\mathrm{O}$ autor completa que o ambiente habitacional apresenta componentes intrínsecos que podem determinar atributos que favoreçam, ou não, a qualidade de vida e o bem-estar do indivíduo que ali habita, sob os aspectos físicos, afetivos, sensoriais e funcionais.

Dessa forma, a moradia constitui um fator importante no processo de envelhecimento no curso de vida. Para a pessoa idosa, a habitação repercute em seu cotidiano, em suas atividades diárias e também em sua saúde, pois esse ambiente, quando adequado, favorece a execução de atividades com segurança e conforto (Braga, Bestetti, \& Franco, 2016).

De acordo com o Guia Global das Cidades Amigas das Pessoas Idosas (OMS, 2008), a moradia é preponderante nas questões relacionadas ao bem-estar e à segurança de qualquer segmento populacional.

Em outros termos, postula-se que o ambiente físico faz parte dos determinantes essenciais elencados para um envelhecimento ativo e saudável. Nas Figuras 1 e 2, são revelados os condicionantes para cidades apropriadas e os condicionantes para um envelhecimento ativo, que se articulam entre si com o intuito de dar mais condição à pessoa idosa para vivenciar o envelhecimento de forma positiva e saudável. 
FIGURAS 1 e 2: Extensões a serem consideradas para uma Cidade Amiga do Idoso; e Determinantes para um Envelhecimento Ativo (respectivamente)
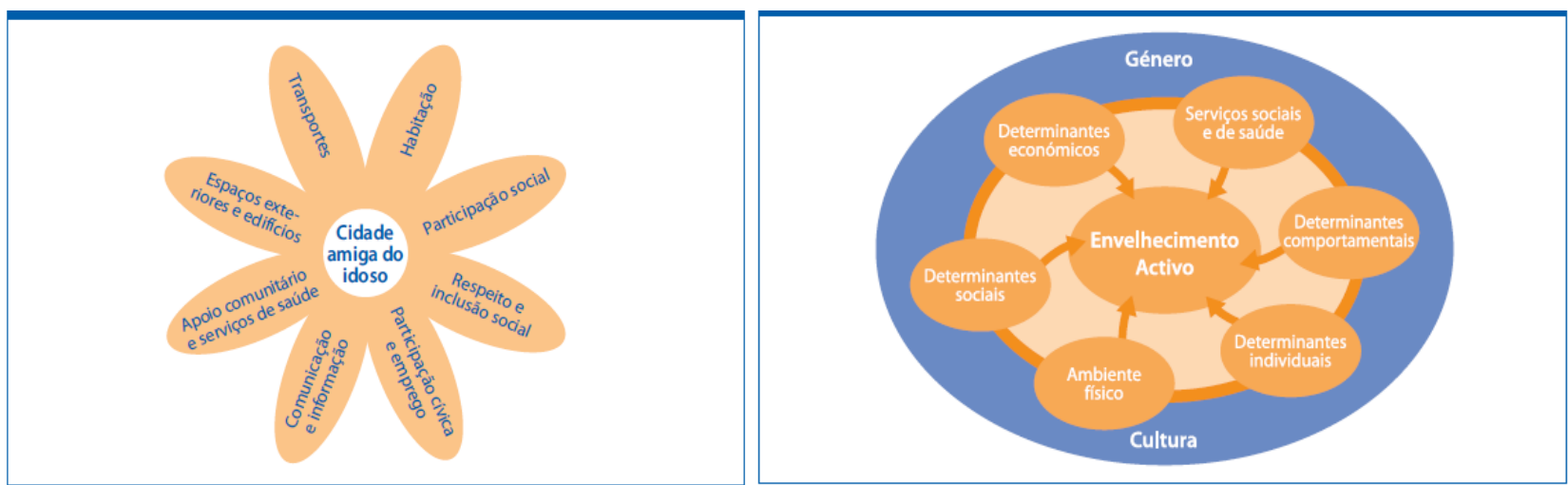

Fonte: Guia Global das Cidades Amigas das Pessoas Idosas (OMS, 2008)

Os dois fatores globais que vêm moldando o século XXI são o envelhecimento populacional e a urbanização, sendo justificável e conveniente pensar em cidades que atendam as pessoas idosas em suas estruturas e serviços, assim como na conscientização da comunidade em que o idoso está inserido, sobre a importância que esses indivíduos têm na construção social de toda a sociedade. Assim, a casa de morar representa um salto na qualidade de vida, por atribuir com valor físico e emocional, e por fazer parte dos determinantes, conforme explicitado pela Organização Mundial da Saúde (OMS, 2008, p. 34):

\footnotetext{
A habitação adequada e o acesso aos serviços comunitários e sociais estão interligados, exercendo influência sobre a independência e a qualidade de vida dos idosos. É evidente que a habitação e os serviços de apoio que permitem aos idosos um envelhecimento confortável e em segurança na comunidade a que pertencem são aspectos universalmente valorizados.
}

O acesso à habitação digna no Brasil é um fator limitante para a população em geral, em especial quando se trata da população de baixa renda. Para a população idosa carente, então, este fato se torna ainda mais dramático (Bonduki, 2008; Gandini, Barione, \& Souza., 2012; Costa, Plouffe, Voelcker, \& Kalache, 2016). 
A partir desse entendimento, o Estado da Paraíba lançou uma iniciativa pioneira, por meio da Companhia Estadual de Habitação Popular (CEHAP) e da Secretaria de Estado de Desenvolvimento (SEDH), ao idealizar e desenvolver o projeto intitulado Cidade Madura, implantado na capital do estado, João Pessoa. O projeto é destinado à população idosa que recebe até cinco salários, que seja independente, more só, ou com cônjuge/companheiro também idoso (CEHAP, 2014; Brasil, 2014a). O condomínio Cidade Madura constitui o objeto de estudo deste artigo caracterizado como estudo de caso.

É sempre válido lembrar o marco na discussão acerca do envelhecimento no Brasil e seus contornos. O Estatuto do Idoso (Brasil, 2003) prevê, em seu artigo 37, a oferta de moradia digna e adequada à população idosa, assim como a escolha pelo idoso da forma mais afeita a ele de morar:

Art. 37. O idoso tem direito à moradia digna, no seio da família natural ou substituta, ou desacompanhado de seus familiares, quando assim o desejar, ou, ainda, em instituição pública ou privada.

$\S 1^{\text {o }} \mathrm{A}$ assistência integral na modalidade de entidade de longa permanência será prestada quando verificada inexistência de grupo familiar, casa-lar, abandono ou carência de recursos financeiros próprios ou da família.

$\S 2^{\circ}$ Toda a instituição dedicada ao atendimento ao idoso fica obrigada a manter identificação externa visível, sob pena de interdição, além de atender toda a legislação pertinente.

§ 30 As instituições que abrigarem idosos são obrigadas a manter padrões de habitação compatíveis com as necessidades deles, bem como provê-los com alimentação regular e higiene indispensáveis às normas sanitárias e com estas condizentes, sob as penas da lei.

Art. 38. Nos programas habitacionais, públicos ou subsidiados com recursos públicos, o idoso goza de prioridade na aquisição de imóvel para moradia própria, observado o seguinte:

I - Reserva de pelo menos 3\% (três por cento) das unidades habitacionais residenciais para atendimento aos idosos;

II - Implantação de equipamentos urbanos comunitários voltados ao idoso;

III - Eliminação de barreiras arquitetônicas e urbanísticas, para garantia de acessibilidade ao idoso; 
IV - Critérios de financiamento compatíveis com os rendimentos de aposentadoria e pensão.

Parágrafo único. As unidades residenciais reservadas para atendimento

a idosos devem situar-se, preferencialmente, no pavimento térreo (Brasil, 2003, s.p.).

Diante do exposto, o principal objetivo deste trabalho foi identificar os aspectos de uma moradia adequada para a pessoa idosa, a fim de compreender a repercussão de tais elementos em sua vida. Tendo em vista que a habitação é fator crucial na qualidade de vida da pessoa idosa, pressupõe-se a relevância deste estudo para o entendimento da relação casa e indivíduo e suas repercussões.

\section{Percurso Metodológico}

Caracteriza-se, a metodologia adotada, como descritiva, de caráter qualitativo, pois foi desenvolvida uma pesquisa bibliográfica/documental para embasar o estudo de caso, constituído por registro fotográfico e observação direta. Dessa forma, buscou-se analisar a estrutura física do condomínio, assim como a percepção de alguns idosos moradores do local, por meio de conversa despretensiosa.

Depois de contato telefônico com a CEHAP, foi autorizada a visita ao Condomínio Cidade Madura, sendo agendados a data e o horário (dia 01/05/2017, no período da tarde). A visita teve duração de todo o turno da tarde, com acompanhamento de uma funcionária da CEHAP. A pesquisadora pôde conversar com os moradores, andar pelo condomínio em todos os ambientes, fotografar e filmar o local.

Vale pontuar que este estudo de caso é parte integrante da pesquisa de campo componente da futura tese de doutorado na área de envelhecimento e arquitetura, pela Universidade Federal de Viçosa (MG).

\section{Resultados e Discussão}

A escolha específica pelo Condomínio Cidade Madura foi em razão de sua iniciativa pioneira. Sua implementação advém de uma política pública na esfera estadual que é atrelada aos direitos da pessoa idosa. 
O condomínio foi inaugurado pelo governo do Estado da Paraíba, por meio da CEHAP, integrando um programa de habitação criado pelo Decreto n. ${ }^{0} 35.072$ (Brasil, 2014a). Sua construção foi iniciada em 2011, sendo concluído e entregue em junho de 2014.

Com o objetivo de abrigar idosos que não têm como adquirir suas casas próprias, mas que conseguem viver sozinhos, o Condomínio Cidade Madura foi implantado em diferentes cidades (João Pessoa, Campina Grande, Cajazeiras, Guarabira, tendo previsão para o município de Pato, ainda no ano de 2019). Assegurar os direitos sociais e fortalecer vínculos comunitários, além de favorecer a dignidade e autonomia dos idosos, são determinantes implementados no projeto do condomínio e na política pública estadual.

Em seu cerne, o projeto tem por princípio a acessibilidade e a exclusividade da população idosa de baixa renda, de ambos os sexos, e residente na cidade de João Pessoa há pelo menos dois anos (CEHAP, 2014; Brasil, 2014b).

Conforme proposta esquematizada na Figura 3, a Cidade Madura é uma copropriedade fechada horizontal, com vocação residencial e comercial, estando localizada no bairro Mangabeiras. Trata-se de um bairro periférico, considerado o mais populoso da cidade de João Pessoa, e que é abastecido com equipamentos urbanos, transporte, hospital próximo e comércio (CEHAP, 2014).

FIGURA 3: Implantação e descrição dos espaços disponíveis

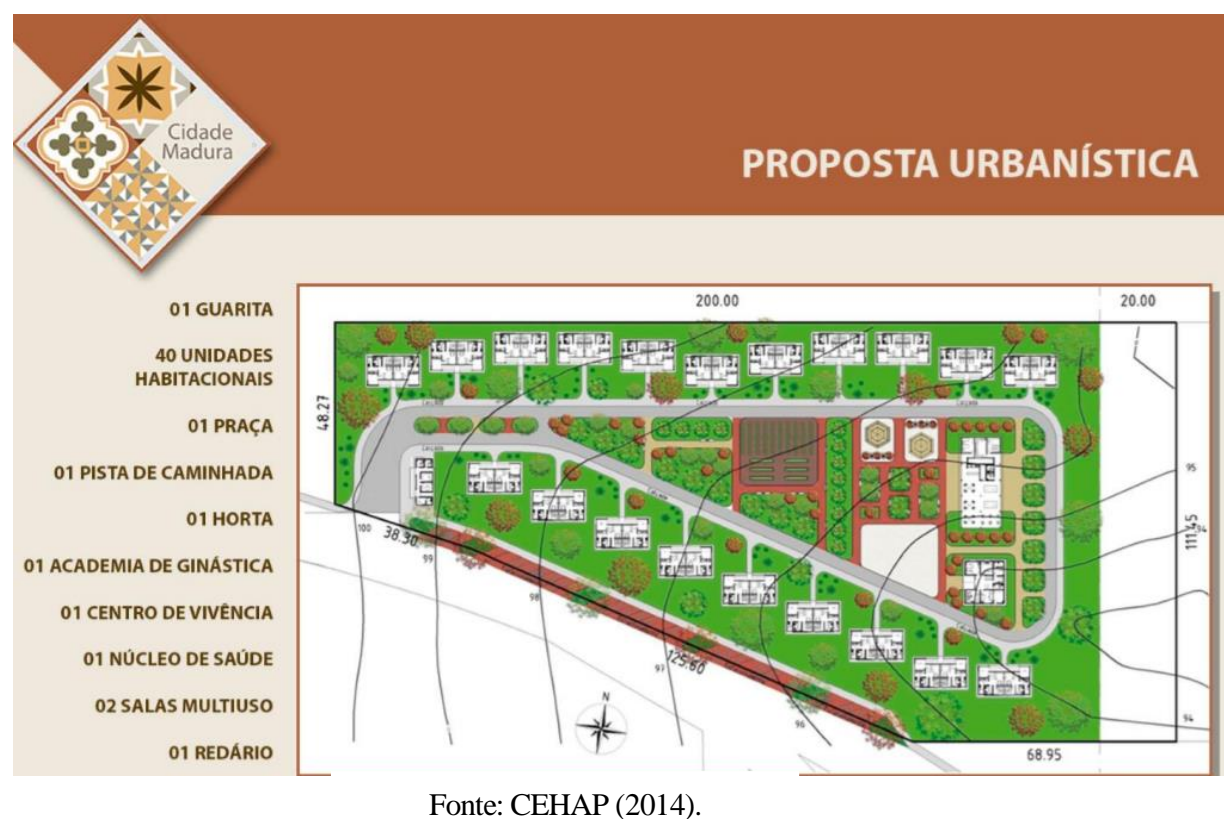

Miguel, E. N., \& Mafra, S. C. T. (2019). O Condomínio Cidade Madura: um estudo de caso de uma nova maneira de morar da pessoa idosa brasileira. Revista Kairós-Gerontologia, 22(3), 211-226. ISSNprint 1516-2567. ISSNe 2176901X. São Paulo (SP), Brasil: FACHS/NEPE/PEPGG/PUC-SP 
Conforme ilustrado na figura anterior, o condomínio é dotado de 40 (quarenta) unidades habitacionais, praça, academia ao ar livre, horta comunitária, salão para atividades físicas e sociais, pista de caminhada, além de um núcleo de saúde com consultório médico e de fisioterapia.

FIGURA 4: Visão externa do Centro de Vivência e Núcleo de Saúde

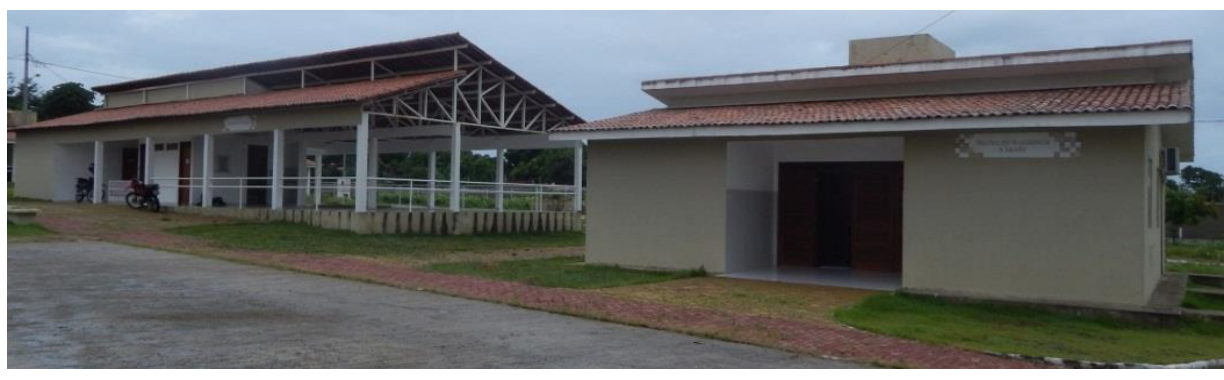

Fonte: Arquivo próprio (2017)

Como atividade desenvolvida regularmente, tem-se a aula de educação física, uma vez por semana, realizada no Centro de Vivência, ou ao ar livre. Outras atividades como dança, apresentação, palestras, reuniões, festas temáticas e aulas específicas podem ser agendadas ao longo do ano. Essas atividades estimulam a saúde física e psicológica da pessoa idosa, assim como sua interação e participação social.

Outro fator importante a salientar é a quebra do ciclo vicioso que o ócio promove a uma gama considerável de idosos (Lima, 2011). Sabe-se que a falta de ocupação do tempo, muitas vezes, faz adoecer a pessoa que vivencia a velhice.

FIGURAS 5, 6 e 7: Repartições internas do Núcleo de Saúde

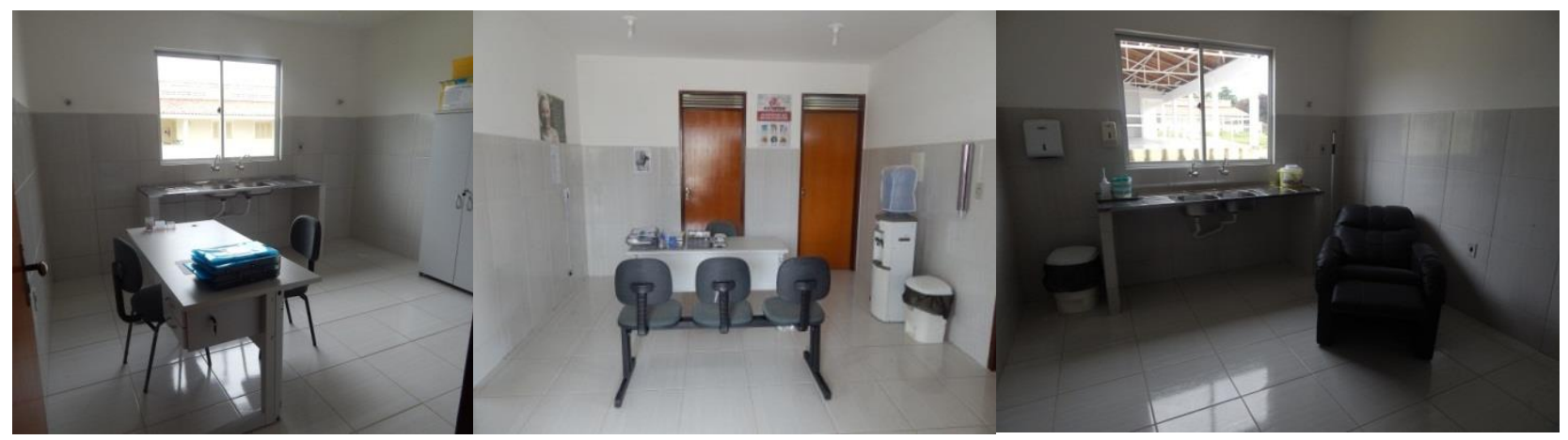

Fonte: Arquivo próprio (2017) 
Entre os servidores disponibilizados no condomínio, destacam-se: uma técnica de enfermagem, que permanece durante o dia para efetuar o atendimento básico de saúde (aferição de pressão, e auxílio com a medicação) e um médico, que atende os moradores em consultas mensais. O consultório médico e fisioterápico, assim como a recepção, são ambientes confortáveis para a realização de consultas, como pode ser visto nas Figuras 5, 6 e 7.

Em conversa informal com a técnica de enfermagem que trabalha no condomínio, e que tem experiência com o Programa de Saúde da Família, ela afirmou que esse modelo de assistência é mais efetivo por se tratar de idosos que convivem com outros idosos diariamente, locados bem próximos ao núcleo de saúde (situado dentro do condomínio). Além de se identificarem entre si com relação à idade, não acarretando, assim, nenhuma forma de Idadismo ${ }^{1}$; a interação social favorece a saúde física e emocional. Interação social que se dá por meia das atividades comunitárias, caminhadas, exercícios ao ar livre, conversas nos bancos da praça, reuniões e encontros oferecidos no salão multiuso, e manutenção da horta comunitária são exemplos de interação social praticada pelo grupo de moradores do condomínio (Figuras 8, 9, 10, e 11).

FIGURAS 8, 9, 10 e 11: Área para lazer, academia ao ar livre, praça e horta (respectivamente)
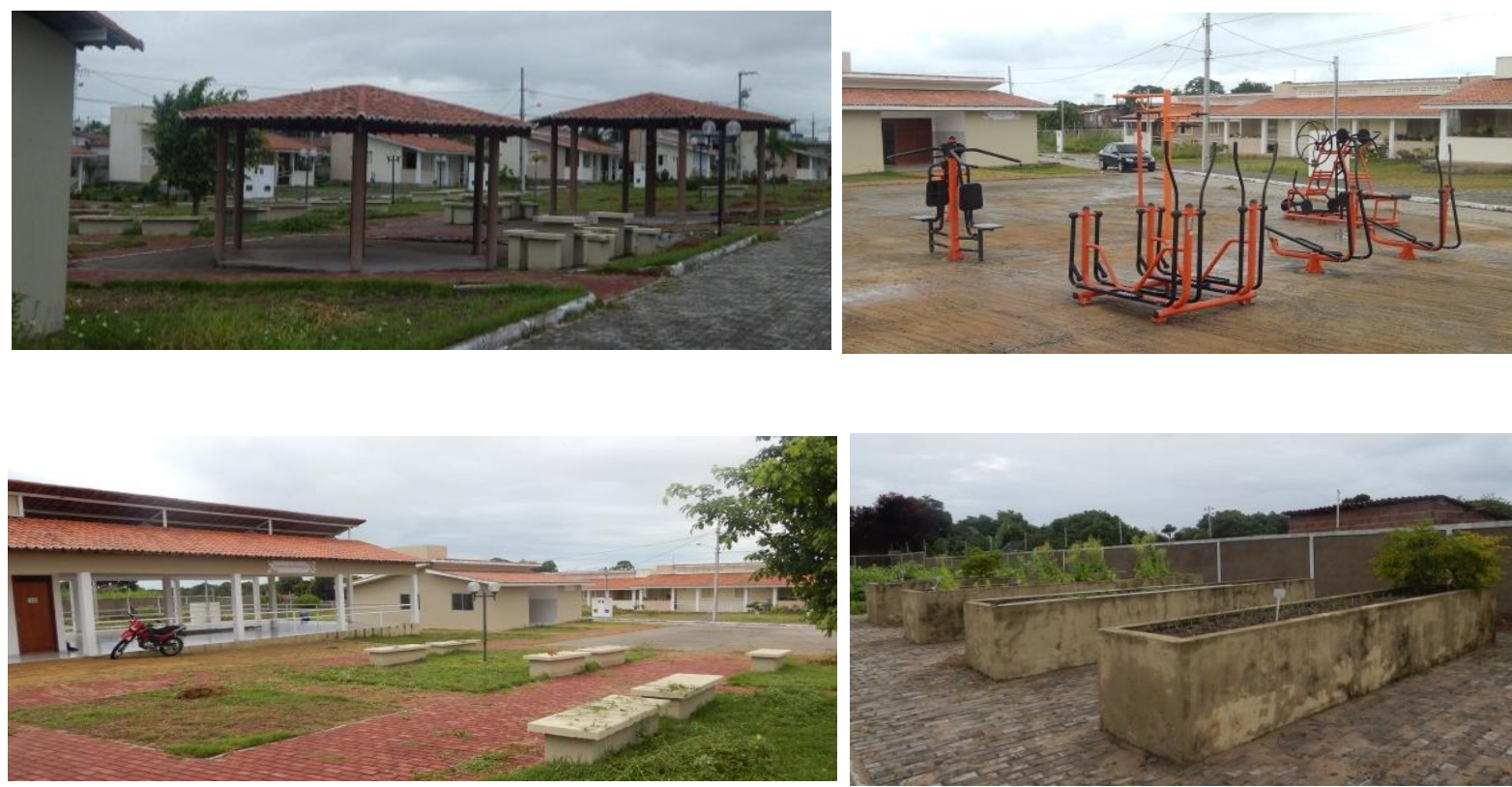

Fonte: Arquivo próprio (2017)

\footnotetext{
${ }^{1}$ Idadismo ou Ageísmo é o conceito que designa uma modalidade de preconceito social - o etário - que, muitas vezes, sem que as pessoas se deem conta de sua afetação por este, pode se manifestar e trazer efeitos prejudiciais a um idoso, marcando-o especialmente em termos subjetivo-sociais (Souza-Guides, \& Lodovici, 2018; Sousa, Lodovici, \& Silveira, 2014).
}

Miguel, E. N., \& Mafra, S. C. T. (2019). O Condomínio Cidade Madura: um estudo de caso de uma nova maneira de morar da pessoa idosa brasileira. Revista Kairós-Gerontologia, 22(3), 211-226. ISSNprint 1516-2567. ISSNe 2176901X. São Paulo (SP), Brasil: FACHS/NEPE/PEPGG/PUC-SP 
Vale ressaltar a importância da adequação da casa para os idosos, assim como o ajustamento das vias e ambientes comunitários utilizados por eles, tais como espaços de fluxos, espaços públicos e equipamentos urbanos (Kunst, 2016). Nesse sentido, o condomínio procurou atender ao requisito de acessibilidade dentro das residências e também nas áreas externas de uso comunitário, como ilustrado nas figuras anteriores e a seguir.

FIGURAS 12 e 13: Guarita e Entrada do Condomínio

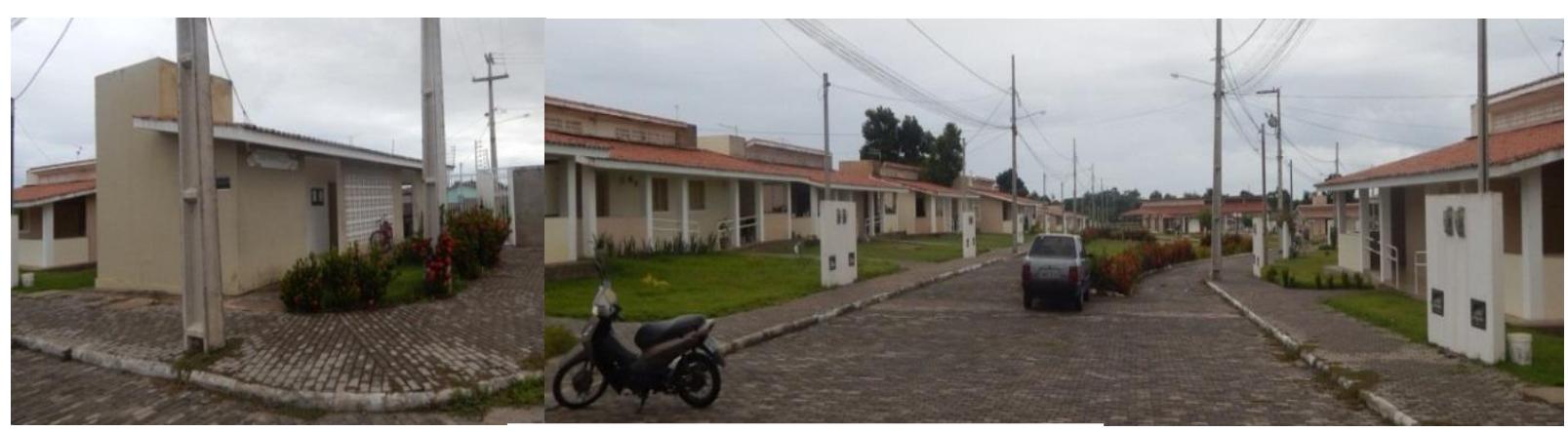

Fonte: Arquivo próprio (2017)

O condomínio possui uma guarita com porteiro $24 \mathrm{~h}$ em sua entrada, conferindo segurança e apoio, caso aconteça algum imprevisto com os moradores. A parte administrativa também é localizada na entrada do condomínio, na mesma edificação da guarita (Figura 12).

Como pode ser observado na Figura 13, as vias são pavimentadas e possuem baixa inclinação. A manutenção de toda a área comum (ruas, praça e jardinagem) é de responsabilidade do governo do Estado, assim como os demais custos do condomínio. Adicionalmente, os moradores contribuem com uma taxa de condomínio mensal, sendo responsáveis também por suas despesas domiciliares.

As casas são geminadas de duas em duas, tendo, em cada unidade habitacional, $54 \mathrm{~m}^{2}$ distribuídos em varanda, sala, cozinha, quarto e banheiro adaptado acessível. A definição de apenas um quarto por moradia é em razão da vocação do projeto, destinado a pessoas idosas que moram sozinhas ou com os cônjuges. A ideia é dar protagonismo ao idoso e evitar a acomodação de parentes, fato este recorrente em muitas famílias. 
Há apenas uma concessão de uso, sendo o imóvel pertencente ao Estado da Paraíba. No caso de falecimento ou de perda de independência e/ou autonomia do idoso residente, o imóvel é encaminhado à família ou a alguma ILP (Instituição de Longa Permanência). Assim, outro idoso, que já faz parte da fila de espera, passa a morar nessa casa (CEHAP, 2014; Kunst, 2016).

Para preservar o projeto e a acessibilidade da moradia, é vetado aos usuários qualquer tipo de intervenção, além de não ser permitida a disponibilidade de alugar ou ceder o imóvel, por parte do idoso morador.

FIGURAS 14 e 15: Planta baixa e Fachada da casa (dupla geminada)

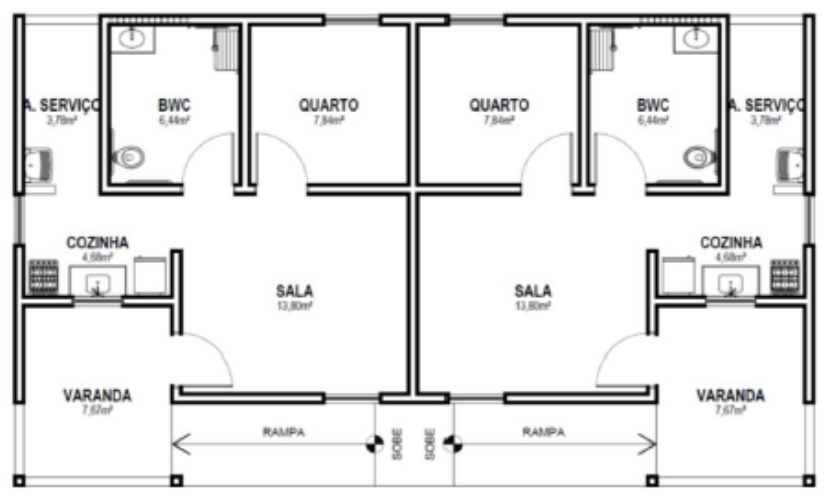

Fonte: Arquivo próprio (2017)

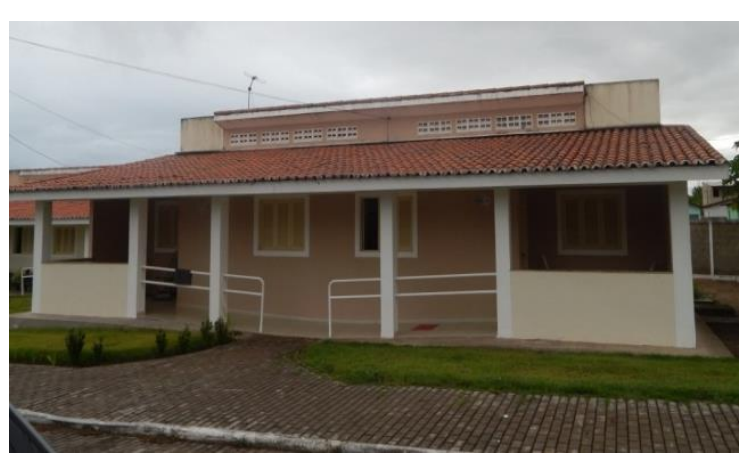

Fonte: CEHAP (2014)

É válido ressalvar que existe uma perda na qualidade de insolação e ventilação nas moradias. Por serem geminadas e as plantas rebatidas, ambientes como, por exemplo, o quarto, em algumas casas, tomam orientação solar a oeste, aspecto não desejável para o quarto de dormir (é desejável orientação a leste, mas nem todas usufruem dessa posição, devido à rotação da planta de implantação e ao rebate das plantas baixas).

A adequação dos banheiros vale destaque em razão de ser um dos ambientes nos quais mais ocorrem acidentes, muitas vezes graves. Como demonstrado nas Figuras 16 e 17, o banheiro possui barras de segurança, assento para o banho e sem a presença de box fixo, elementos que favorecem a segurança e se adequam ao protocolo de acessibilidade. Entretanto, o desnível na área do banho não deveria existir, uma vez que esse ressalto pode causar tropeção e/ou queda do idoso. Além disso, o piso desse ambiente deveria ser mais antiaderente, a nosso ver. 
FIGURAS 16 e 17: Visão interna do banheiro de uma unidade habitacional

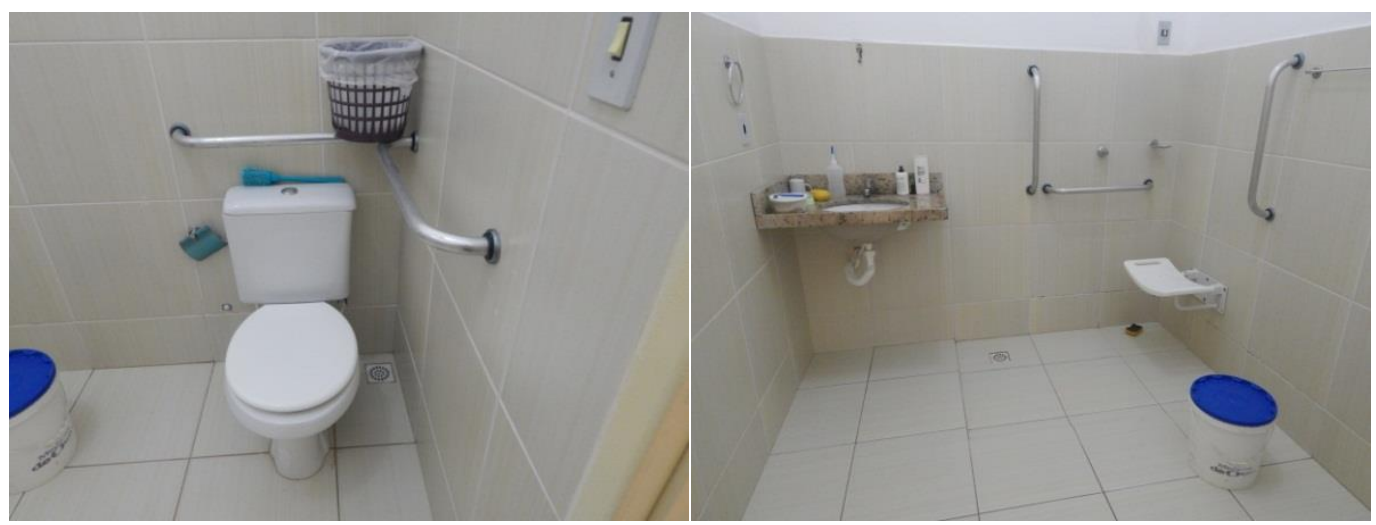

Fonte: Arquivo próprio (2017)

Geralmente, as quedas que acomentem os idosos decorrem da eventual perda do equilíbrio postural ${ }^{2}$ há, nessa fase de vida, uma dificuldade em se manter a postura corporal. A mesma falta de equilíbrio pode ser potencializada com a perda da aquidade visual e auditiva, que também integram o processo natural do envelhecimento humano. A queda pode provocar danos físicos graves na faixa etária idosa, como danos mentais, aumentando, assim, a taxa de morbilidade e mortabilidade.

Nesse contexto, há uma combinação dos fatores intrínsecos e extrínsecos para a queda. Os fatores intrínsecos dizem respeito às modificações fisiológicas, efeitos medicamentosos e condições inerentes a alguma patologia; os extrínsecos, por sua vez, estão diretamente correlacionados às questões e condições ambientais e seus perigos (Knijnik, et al., 2019). Nesse sentido, a inadequação física da moradia, as barreiras arquitetônicas, a falta de conforto e de segurança nos ambientes colaboram para a dependência do idoso em seu espaço domiciliar (Cunha, \& Guimarães, 1989; Gomes, Marques, Leal, \& Barros, 2014).

De Deus (2010) confirma que a adequação das condições físicas da casa faz parte do conceito de moradia digna e adequada, abrangendo: habitabilidade; oferta de serviços, infraestrutura e equipamentos públicos; localização adequada; custo acessível; e adequação de cultura. Miguel, et al. (2016) concordam que o direito à moradia está intimamente ligado à adequação do ambiente onde se vive. Do mesmo modo, Rolnik (2010, p. 4) apregoa que "toda a pessoa tem direito a um padrão de vida adequado para si

\footnotetext{
${ }^{2}$ Equilíbrio corporal entendido como a capacidade de o ser humano manter-se ereto, executando movimentos de aceleração e rotação do corpo sem oscilações ou quedas (Knijnik, et al., 2019).
} 
e sua família, inclusive à moradia adequada, assim como a uma melhoria contínua de suas condições de vida".

O condomínio Cidade Madura, na cidade de João Pessoa, capital do estado da Paraíba, é uma iniciativa que coloca luz à questão delicada da moradia do idoso brasileiro de baixa renda. Pensar na casa de morar, assim como em seus ambientes acessíveis e adequados, confere dignidade e bem-estar ao idoso, favorecendo, assim, sua qualidade de vida.

\section{À guisa de conclusão}

Envelhecer é uma conquista da sociedade, processo almejado ao longo da história de todo o indivíduo. O Condomínio Cidade Madura é um exemplo de planejamento no que diz respeito à forma de se morar e de viver, esta associada às questões ligadas ao envelhecimento, com o objetivo de agregar valor em detrimento da qualidade de vida da pessoa idosa.

Apesar de haver problemas e limitações no projeto, evidencia-se o avanço proporcionado pelo governo do Estado, no que tange ao cuidado disponibilizado ao idoso brasileiro de baixa renda.

No Brasil, existem alguns empreendimentos de condomínios exclusivos para essa faixa etária, assim como em todo mundo. No entanto, são de alto custo para a pessoa, atendendo apenas às classes econômicas mais favorecidas. Este é o diferencial do condomínio Cidade Madura dentro da política de habitação; trata-se de um programa estadual que abarca a população menos favorecida e que atende as demandas desta população quanto à moraria e assistência.

Tal iniciativa configura, portanto, uma evolução, já que o condomínio atende razoavelmente as questões físicas de moradia e de áreas externas de uso comum, com acessibilidade e ambientes socializáveis, como o jardim e a horta comunitária.

Não se pode olvidar alguns problemas, como a sua localização, que favorece o isolamento do idoso, além de haver baixa oferta de equipamentos públicos.

A habitação da pessoa idosa é um tema de pesquisa relevante, uma vez que há urgência nesta demanda da população, havendo ainda poucas iniciativas públicas para tal. Políticas públicas que abarquem a população idosa carente, com vistas à casa dotada de acessibilidade e que imprima dignidade ao indivíduo, são, de fato, um desafio para o poder público neste século. 


\section{Referências}

Bonduki, N. (2008). Política habitacional e inclusão social no Brasil: revisão histórica e novas perspectivas no governo Lula. São Paulo, SP: Revista Eletrônica de Arquitetura e Urbanismo, 1, 70-104. Recuperado em 05 junho, 2014, de: http://www.usjt.br/arq.urb/ numero_01/artigo_05_180908.pdf.

Braga, A. A., Bestetti, M. L. T., \& Franco, F. G. de M. (2016). O Conforto na Ambiência de Idosos Moradores em Instituições de Longa Permanência. São Paulo (SP): PUC-SP: Revista Kairós-Gerontologia, 19(2), 327-347. ISSNprint 1516-2567. ISSNe 2176-901X. Recuperado em 01 dezembro, 2018, de: https://revistas.pucsp.br/kairos/article/view/ $35725 / 24555$.

Brasil. (2003). Estatuto do idoso: Lei Federal n. 10.741 , de 01 de outubro de 2003. Recuperado em 05 junho, 2014, de: http://www.planalto.gov.br/ccivil_03/leis/2003/110.741.htm.

Brasil. (2014a). Decreto Estadual n. ${ }^{\circ} 35.072$ de 10 de junho de 2014. Institui o Programa Habitacional Cidade Madura, e dá outras providências. Prefeitura do estado da Paraíba, Brasil. Recuperado em 01 dezembro, 2018, de: http://static.paraiba.pb.gov.br/2014/06/Diario-Oficial-11-06-2014.pdf.

Brasil. (2014b). __ Governo do Estado entrega Residencial Cidade Madura na capital. Prefeitura da Paraíba. 2014b. Recuperado em 24 fevereiro, 2018, de: http://www.paraiba.pb.gov.br/91022/governo-do-estadoentrega-residencial-cidademadura-em-joao-pessoa-na-terca-feira.html.

Camarano, A. A., Kanso, S., \& Mello, J. L. (2004). Como vive o idoso brasileiro? In: Camarano, A. A. (Org.). Os novos idosos brasileiros muito além dos 60?, 25-76. Rio de Janeiro, RJ: IPEA.

CEHAP. (2014). Companhia Estadual de Habitação Popular da Paraíba. Programa: Cidade Madura. João Pessoa, Paraíba. Recuperado em 24 fevereiro, 2018, de: http://www.cehap.pb.gov.br/site/cidade-madura.html.

Costa, S., Plouffe, L., Voelcker, I., \& Kalache, A. (2016). Habitação e Urbanismo. In: Alcântara, A. de O., Camarano, A. A., \& Giacomin, K. C. (Orgs.). Política Nacional do Idoso: velhas e novas questões, 295-322. Rio de Janeiro, RJ: IPEA. Recuperado em 24 fevereiro, 2018, de: http://sbgg.org.br/wp-content/uploads/2016/10/Pol\%C3\%ADticaNacional-do-Idoso-velhas-e-novas-quest\%C3\%B5es-IPEA.pdf.

Cunha, U. V., \& Guimarães, R. M. (1989). Sinais e sintomas do aparelho locomotor. Sinais e sintomas em geriatria, 141-154. Rio de Janeiro, RJ: Revinter.

De Deus, S. I. A. (2010). Um modelo de moradia para idosos: o caso da Vila dos Idosos do Pari-São Paulo, SP. Revista Kairós-Gerontologia, 13(Número Especial 8, "Moradia na Velhice"), 195-213. DOI: 10.23925/2176-901X.2010v13iEspecial8p195-213. Recuperado em 01 dezembro, 2018, de: https://revistas.pucsp.br/kairos/article/view/6922/5014.

Fonseca, S. C. (2016). (Org.). O Envelhecimento Ativo e seus fundamentos. São Paulo, SP: Portal Edições. ISBN: 978-85-6935-06-4.

Gandini, J. A. D., Barione, S. F., \& Souza, A. E. D. (2012). Políticas habitacionais para idosos: avanços e desafios. In: Berzins, M. V., \& Borges, M. C. (Eds.). Políticas públicas para um país que envelhece, 181-208. São Paulo, SP: Martinari. 
Gomes, E. C. C., Marques, A. P. de O., Leal, M. C. C., \& Barros, B. P. de. (2014). Fatores associados ao risco de quedas em idosos institucionalizados: uma revisão integrativa. Revista Ciência \& Saúde Coletiva, 19(8) 3543-3551. Recuperado em 01 dezembro, 2018, de: https://doi.org/10.1590/1413-81232014198.16302013.

Knijnik, S. R., Fifer, R., Santos, S. B. dos, Soldera, C. L. C., Knijnik, G. J., Bós, Â. J. G., \& Terra, N. L. (2019). Manutenção do equilíbrio corporal: perspectivas futuras. São Paulo, SP: PUC-SP: Revista Kairós-Gerontologia, 22(1), 231-247. ISSNprint 15162567. ISSNe 2176-901X. Recuperado em 01 dezembro, 2018, de: DOI: https://revistas.pucsp.br/kairos/article/view/43417.

Kunst, M. H. (2016). Avaliação da acessibilidade do idoso em conjuntos habitacionais: O caso do Cidade Madura. Dissertação de mestrado em Desenvolvimento Urbano. Universidade Federal de Pernambuco, Recife, PE. Recuperado em 01 dezembro, 2018, de: https://repositorio.ufpe.br/handle/123456789/21579.

Lima, A. B. R. (2011). Ambiente residencial e envelhecimento ativo: estudos sobre a relação entre bem-estar, relações sociais e lugar na terceira idade. Tese de doutorado. Brasília, DF: UnB. Recuperado em 01 dezembro, 2018, de: https://repositorio.unb.br/handle/10482/10277.

Miguel, E. N., Mafra, S. C. T., \& Fontes, M. B. (2016). O morar contemporâneo do idoso: onde e como reside no estado de Minas Gerais. Dissertação de mestrado em Economia Doméstica. Universidade Federal de Viçosa, Viçosa, MG, Brasil. Recuperado em 01 dezembro, 2018, de: https://www.locus.ufv.br/bitstream/handle/123456789/8179/ texto $\% 20$ completo.pdf?sequence $=1 \&$ isAllowed $=\mathrm{y}$.

OMS. (2008). Organização Mundial da Saúde. Guia global: Cidade Amiga do Idoso. Genebra, Suíça: OMS. Recuperado em 01 dezembro, 2018, de: https://www.who.int/ageing/GuiaAFCPortuguese.pdf.

Perracini, M. R. (2006). Planejamento e adaptação do ambiente para pessoas idosas. In: Freitas, E. V., et al. Tratado de geriatria e gerontologia, 1142-1151. (2 ${ }^{\mathrm{a}}$ ed.). Rio de Janeiro, RJ: Guanabara Koogan.

Rolnik, R. (2010). Como atuar em projetos que envolvem despejos e remoções. Relatoria especial da ONU para a moradia adequada. São Paulo, SP, Brasil. Recuperado em 01 dezembro, 2018, de: https://raquelrolnik.files.wordpress.com/2010/01/guia_portugues.pdf.

Sousa, A. C. S. N., Lodovici, F. M. M., Silveira, N. D. R., \& Arantes, R. P. G. (2014). Alguns apontamentos sobre o Idadismo: a posição de pessoas idosas diante desse agravo a sua subjetividade. Estudos Interdisciplinares sobre o Envelhecimento, 19(3), 853-877. Recuperado em 01 dezembro, 2018, de: http://seer.ufrgs.br/RevEnvelhecer/search/search.

Souza-Guides, A. C. N. de, \& Lodovici, F. M. M. (2018). O Idadismo/Ageísmo sob a escuta dos idosos: efeitos de sentido e a utopia de um novo envelhecer. In: Lodovici, F. M. M. (Org.). Envelhecimento e Cuidados - uma chave para o viver, 175-210. São Paulo, SP: Portal Edições. ISBN: 978-85-69350-15-6. 
Recebido em 12/07/2019

Aceito em 30/09/2019

Eleusy Natália Miguel - Economista Doméstica, Arquiteta e Urbanista. Mestre em Economia Doméstica. Doutoranda, Universidade Federal de Viçosa. Especialista em Arte e Cultura Barroca, Universidade Federal de Ouro Preto. Estudante de graduação de Serviço Social, UNIFRAN. Professora na Univiçosa, FACISA, no curso de Arquitetura e Urbanismo.

URL: https://orcid.org/0000-0002-9464-0820

E-mail: eleusy.arq@gmail.com

Simone Caldas Tavares Mafra - Economista Doméstica, Universidade Federal de Viçosa. Pós-doutorado, no Sealy Center on Aging, University of Texas Medical Branch, Texas, Estados Unidos. Doutorado e mestrado em Engenharia de Produção, Universidade Federal de Santa Catarina. Professora Titular da Universidade Federal de Viçosa, Viçosa, MG, Brasil.

URL: https://orcid.org/0000-0003-2247-2327

E-mail: sctmafra@ufv.br 